\title{
ANALYSIS MOORING SYSTEM CONFIGURATION OF SUBMERGED FLOATING TUNNEL
}

\author{
Dita Kamarul Fitriyah $^{1}$, Budi Suswanto ${ }^{2}$, Endah Wahyuni ${ }^{3}$ \\ ${ }^{1}$ Master Student Department of Civil Engineering, ITS, Surabaya, Indonesia \\ ${ }^{2}$ Lecture Department of Civil Engineering, ITS, Surabaya, Indonesia \\ ${ }^{3}$ Lecture Department of Civil Engineering, ITS, Surabaya, Indonesia \\ e-mail: Ditaka_fitriyah@yahoo.com
}

\begin{abstract}
Submerged Floating Tunnels (SFT) is a tubular structure that is submerged and floating in depth remains through the system of anchors consisting of a cable connected to the seabed. SFT structure imposed its own weight and is assisted by the buoyancy or uplift caused by water, cross sectin of the tunnel is designed so that buoyancy can overcome the structural weight and experienced a lift force that causes the floating structure. Fastening system (mooring system) also play a role which is to inhibit the SFT structure, minimize displacement and stress caused by environmental burden, such as earthquakes and hydrodynamic load that can aggravate the condition SFT structure in case of crossing the sea with SFT system. SFT will give a fairly small impact on the environment as it floated in the water, and with built using a modular system, the SFT (Submerged Floating Tunnels) can reach a distance long enough and does not cause pollution. Basically the same as the force that occurs archimides principle, where the objects are in the water to get a compressive force to the top. Cross sectional analysis SFT, will be modeled by 7 different models that have been in previous studies. The model's of SFT with steel cable to hold the structure in order to remain strong with the inclination selected. Analysis is done by modeling the triangle wiring configuration with different angle of incliflation cable. The analysis by comparing the test model were made earlier with prototype analyzed numerically. The expected structure did not undergo excessive deformation due to the environmental burden. Therefore, the structure of the SFT will be done with the Abaqus as finite element analysis. So, obvious deformation occurred in the cable. Therefore, it was expected to obtain the optimum angle of inclination was $54^{\circ}$.
\end{abstract}

Keywords: Submerged Floating Tunnels (SFT), Mooring System, Modeling, Configuration Cable Position

\section{INTRODUCTION}

Water crossing is one of the most important issues in this modern world of civil engineering, such as the crossing system is a demand in some places around the world. One of the traditional system that bridges the cable bridge, such as a suspension bridge or a cable stayed bridge, is the most suitable solution in cases where the distance to be traveled. In this case, the presence of crossing airdapat represent the state to take advantage of various terms, this is a new concept on the cable bridge is submerged floating tunnel (SFT) [1].

Submerged Floating Tunnel
is submerged and floating in depth remains throu gh the system of anchors consisting of a cable connected to the seabed. Tunnels are permanently subjected to its own weight and is assisted by the buoyancy caused by water, crosssection of the tunnel is designed so that buoyancy can overcome the structural weight and experience the power of volume directed upwards. The cable system also plays a role which is to inhibit the tunnel, minimize displacement and stress caused by environmental burden, such as earthquakes and hydrodynamic loads that can become severe in the case of sea crossings with SFT system [2].
The stability of the structure of the Submerged Floating Tunnel (SFT) is secured by the anchoring system (mooring system) is adequate, which is made from a steel cable that is at a depth remains on the seabed and connected to the tunnel by means of a ball hinge. Thus, the effect of the configuration of the cable on the structural behavior should be evaluated on the basis of the results of the dynamic analysis [3]. So to reduce the instability of the structure of Submerged Floating Tunnel (SFT) was added to the mooring system with the selected configuration.

\section{A. Structure Cabling System of SFT}

The cable system also plays a role in order
to inhibit the tunnel, to
minimize displacement and stress caused
by environmental burden, such
as seismic actions and hydrodynamics (Mazzola
ni, 2009). Cable system for SFT system is
understood up to now not included
in the typology used for traditional cable-stayed
bridge, because it consists of a group
of wires, placed along the tunnel with or
among a connects directly to the
axis, which cable system will
seabed tunnel. Each cable
be subjected to tensile force due
to buoyancy residual (residual buoyancy), traffi
c loads and its awn
weight, alleviated by the buoyancy, and anchore


d to the seabed through the foundation of the cable group of it [1].

\section{B. Configuration Cable SFT}

The case studies were considered longjunction (L) $150 \mathrm{~m}$ long $80 \mathrm{~m}$ is assumed flat in the middle of the intersection and inclined along the $35-\mathrm{m}$ on either side edges. The depth of the sea floor is set at $21 \mathrm{~m}$, the average water depth archipelago junction (Figure 1). The tunnel was submerged 5-m below the water level and the relationship between the SFT and beaches are set joints. SFT cross

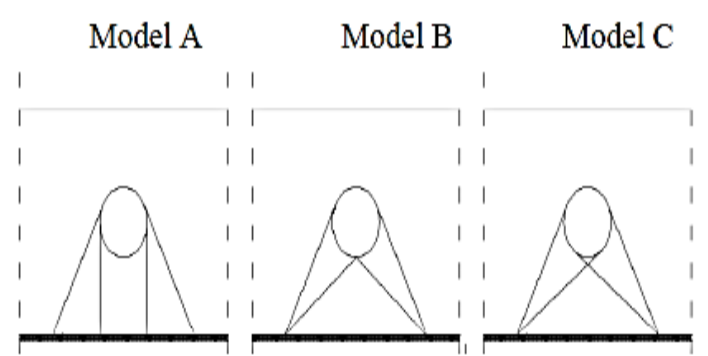

section consists of a steel frame and plate as shown in Figure 1 [6].

Figure 1. Configuration Cable Group of SFT

\section{METHODS}

\section{A. Preparation}

Modeling is divided into various conditions that one condition is used as a parameter modeling. Prototype modeling plan co nfiguration according to Table 1 . The table is taken from one of the variables configuration. The following configurations are studied in particular for the analysis inclination angle position cable with various configurations based on the testing of test models.

Table 1 Configuration Modeling Structure S

\begin{tabular}{|c|c|c|c|c|c|c|c}
\hline 5 & SIK & 9 & 1.2 & 1.5 & A & S-S & 0.65 \\
\hline & & 9 & 1.2 & 1.5 & B & S-S & 0.65 \\
\hline & & 9 & 1.2 & 1.5 & C & S-S & 0.65 \\
\hline & & 9 & 1.2 & 1.5 & D & S-S & 0.65 \\
\hline & & 9 & 1.2 & 1.5 & E & S-S & 0.65 \\
\hline & & 9 & 1.2 & 1.5 & F & S-S & 0.65 \\
\hline & & 9 & 1.2 & 1.5 & G & S-S & 0.65 \\
\hline
\end{tabular}

Description:

- SIK = Angle of Inclination

- Hs = Wave Height

- $\quad$ Ts $=$ Wave Period

In the form of a

numerical modeling analysis using SAP200

0 aid program. Here the

data structure SFT planned according to

Table 2:

Structural Engineering
Table 2 Size SFT prototype

\begin{tabular}{|l|c|c|}
\hline \multicolumn{1}{|c|}{ Magnitude } & Prototype & Units \\
\hline overall length, $\mathrm{L}$ & 150 & $\mathrm{~m}$ \\
\hline Diameter of SFT,D & 5 & $\mathrm{~m}$ \\
\hline Massa of SFT, $\mathrm{m}$ & 2834 & ton \\
\hline buoyancy,B & 1523 & ton \\
\hline
\end{tabular}

The environmental data from the thousand islands that will be used in planning

an effective configuration for SFT structure is as follows on table 3:

Table 3 SFT prototype size

\begin{tabular}{|c|c|c|c|c|c|c|c|}
\hline $\begin{array}{l}\text { Fluid dynamic } \\
\text { environmental }\end{array}$ & Symbol & Unit & Value & Structural Property & Symbol & Unit & Value \\
\hline Fluid density & $\rho$ & $\mathrm{kg} / \mathrm{m}^{3}$ & 1,025 & $\begin{array}{c}\text { Tunnel equivalent } \\
\text { density }\end{array}$ & $\rho T$ & $\mathrm{~kg} / \mathrm{m}^{3}$ & 2,018 \\
\hline Water depth & $h$ & $\mathrm{~m}$ & 20 & $\begin{array}{l}\text { Tunnel outer } \\
\text { diameter }\end{array}$ & $D$ & $\mathrm{~m}$ & 5.5 \\
\hline Wave height & $H$ & $\mathrm{~m}$ & 1.2 & $\begin{array}{l}\text { Tunnel inner } \\
\text { diameter }\end{array}$ & $d$ & $\mathrm{~m}$ & 4.7 \\
\hline Wave period & $T$ & $\mathrm{~m}$ & 3.58 & $\begin{array}{c}\text { Tunnel eauivalent } \\
\text { Young }\end{array}$ & $E T$ & $\mathrm{~N} / \mathrm{m}^{2}$ & $3.2 \times 10^{10}$ \\
\hline $\begin{array}{l}\text { Surface current } \\
\text { velocity }\end{array}$ & UO & $\mathrm{m} / \mathrm{s}$ & 1.2 & Cable density & $\rho C$ & $\mathrm{~kg} / \mathrm{m}^{3}$ & 7,850 \\
\hline Drag coefficient & $C D$ & 1 & 1 & Cable diameter & $d C$ & $\mathrm{~m}$ & 0.1 \\
\hline $\begin{array}{l}\text { Mass/inertia } \\
\text { coefficient }\end{array}$ & $\mathrm{Cm}$ & 1 & 2 & $\begin{array}{l}\text { Cable young } \\
\text { modulus }\end{array}$ & $E C$ & $\mathrm{~N} / \mathrm{m}^{2}$ & $1.4 \times 10^{11}$ \\
\hline $\begin{array}{c}\text { Added-mass } \\
\text { coefficient }\end{array}$ & $\mathrm{Ca}$ & 1 & 1 & $\begin{array}{l}\text { Kinetic viscosity } \\
\text { coefficient }\end{array}$ & $U$ & $\mathrm{~m}^{2} / \mathrm{s}$ & $1.067 \times 10^{-6}$ \\
\hline
\end{tabular}

In a study in the Thousand Islands, the force uplift is $31563.5 \mathrm{KN}$ and total structur al weight is $25770 \mathrm{KN}$, so that the ratio of the power lift and the weight of the structure is 1.22 . This ratio will meet the criteria, ie between 1.2 to 1.3 . So the size of the cross-sectional structure of SFT with $5 \mathrm{~m}$ diameter steel material with $101.7 \mathrm{~mm}$ sling is used as the study of this SFT. For the analysis of the structure, model Finite Element (FE) of this structure created using Abaqus 10.4.

\section{B. Planning}

Other supporting data for this study based on data compiled prototype that has been analyzed previously. The crosssection of data Beikut scaled test model structure based on the prototype

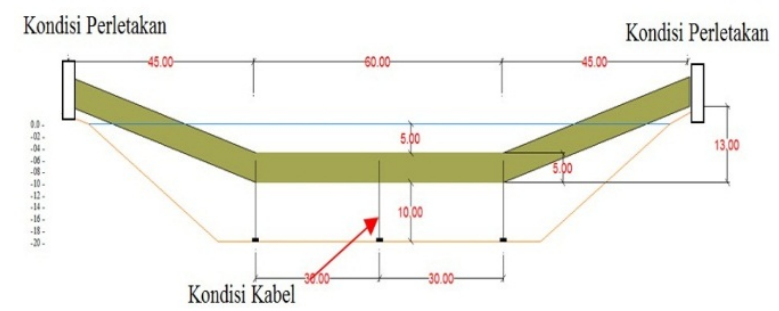

(Fig.2 and Fig.3).

Figure 2. Model Test The scaled

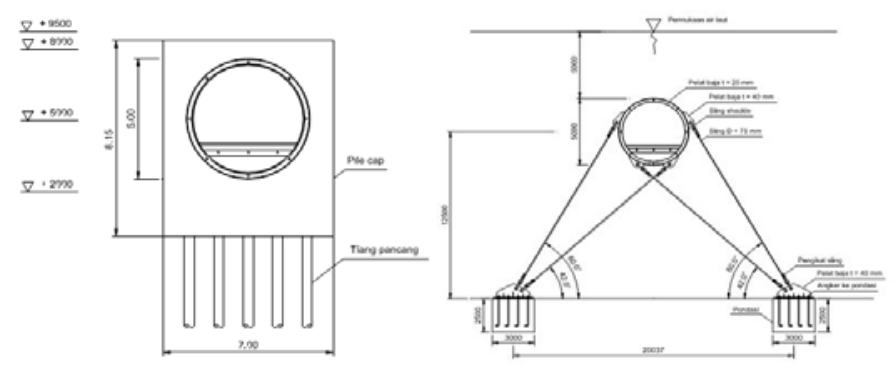


Figure 3. Pieces SFT

\section{Structure Modeling Configuration Cable SFT}

In the early design prototypes of five different cable configurations on previous research, has analyzed and evaluated the behavior of the cable configuration caused by vertical and horizontal load by means of equivalent static analysis and then compared. On the basis of the results achieved, three cable configurations are shown in Figure 2.6 have been. Configuration analysis of the results of the physical predictions, shows that, very effective vertical cables for receiving vertical loads only, whereas selfdefense in the horizontal direction is ignored. Cables tend to be very effective, both in vertical and horizontal directions, only if the fourwire configuration W shape (Fig.4), while the two inclination of cable has a condition defense is not very effective in both vertical and horizontal direction and they give rise to tension torque is relevant in the tunnel, when experienced a horizontal action.
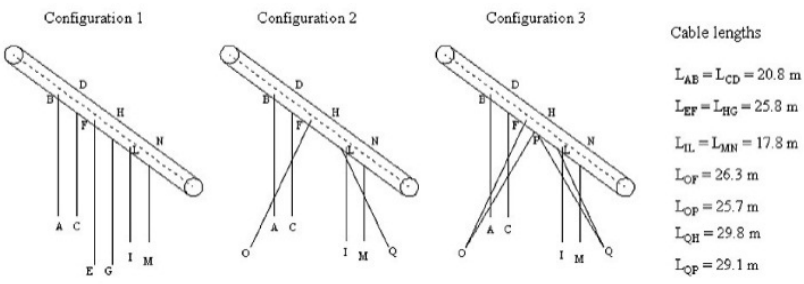

Figure

4. Configuration Cable Prototype SFT
Imposition

of displacement only modeled in one direction only, namely the direction of $\mathrm{x}$ it can be seen in Figure 5. After loading and subsequent meshing running SFT where available stress and the displacement value (Fig.6).

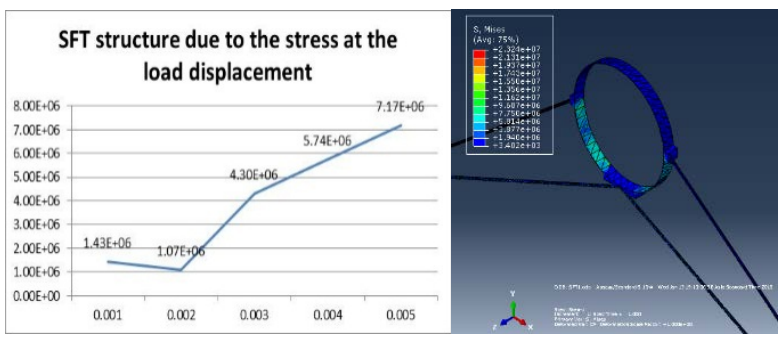

Figure 6. The stress On SFT Structure due to loading displacement

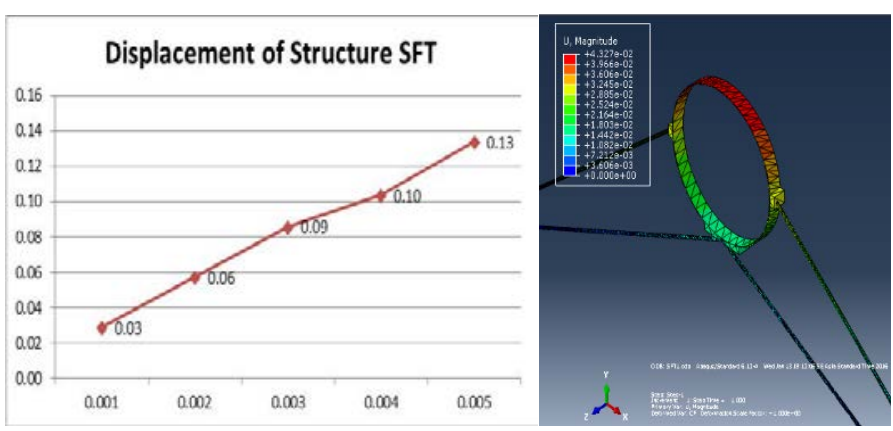

Figure 7. The Displacement On SFT Structure

\section{CONCLUSIONS}

1. In the mooring system modeling over voltage generating value and good reaction. It can be seen in ABAQUS 10.4 modeling results with given load displacement gradual ly.

2. Transfer of the structure due to load displacement that occurs relatively small it can be seen in the difference perpidahan range from approximately $30 \mathrm{~cm}$.

\section{REFERENCES}

[1] Mazzolani, F.M., Faggiano, B., Esposto, M., Martire, G. 2009. A new challenge for strait crossing : the emmersed cable supporting bridge. NSCC2009.

[2] Martinelli, Luca. 2011. A numerical procedure for simulating the multi- support seismic response of submerged floating tunnels anchored by cables. Italy: University of Brescia

[3] Faggiano. 2010. Cable Supported Immersed Inversed Bridge: A challenging proposal. Itali : University of Naples Federico.

[4] Wahyuni, Endah., Raka, I Gusti Putu.,Budiman,Eri. 2012. Dynamic Behaviour of Submerged Floating 
The 2nd International Conference on Civil Engineering Research (ICCER) 2016

"Contribution of Civil Engineering toward Building Sustainable City"

Tunnels under Seismic Loadings with Different Cable Configurations. Surabaya : Institut Teknologi Sepuluh Nopember.

[5] Wahyuni, Endah., Raka, I Gusti Putu.,Budiman,Eri. 2012.

Structural Behaviour Of

Submerged Floating Tunnels

With Different Cable

Configurations Under

Environmental Loading. Surabaya

: Institut Teknologi Sepuluh

Nopember. 